\title{
Perancangan Ulang Tata Letak Fasilitas Produksi Dengan Metode BLOCPLAN (Studi Kasus: UKM Roti Rizki, Bontang)
}

\author{
Moch Adhi Daya*), Farida Djumiati Sitania dan Anggriani Profita \\ ${ }^{1)}$ Jurusan Teknik Industri, Fakultas Teknik, Universitas Mulawarman, Jl. Kuaro, Kota Samarinda, 75119, Indonesia
}

DOI: 10.20961/performa.17.2.29664

\begin{abstract}
Abstrak
Usaha Kecil Menengah (UKM) Roti Rizki merupakan usaha yang bergerak di bidang produksi roti, di antaranya roti tawar, roti manis, dan roti burger. Tata letak fasilitas UKM Roti Rizki saat ini belum mengikuti suatu aturan khusus dalam penempatan peralatan. Mesin-mesin yang digunakan untuk proses produksi tidak memperhatikan aliran proses produksi. Hal ini dapat mengakibatkan ruang gerak para pekerja menjadi terbatas, serta terjadi pengulangan kegiatan yang mengakibatkan pemborosan waktu, proses produksi menjadi tidak efisien yang pada akhirnya akan menurunkan produktivitas produksi. Metode yang digunakan dalam penyelesaian permasalahan ini adalah dengan metode BLOCPLAN. Metode ini dapat menyelesaikan permasalahan tata letak fasilitas pada UKM Roti Rizki dengan tingkat kedekatan hubungan, kebutuhan luas area, memperhitungkan jarak perpindahan material dan tata letak akhir. Luas area pada UKM Roti Rizki sebesar 100 m2, kebutuhan luas area secara keseluruhan sebesar 67,599 m2. Terdapat 20 alternatif tata letak pada metode BLOCPLAN, layout usulan yang dipilih berdasarkan dari nilaii $R$-Score yang nilainya mendekati 1 yaitu layout ke-13 dengan efisiensi jarak perpindahan material sebesar 11,35 meter atau sebesar 3,79\%.
\end{abstract}

Kata kunci: tata letak fasilitas, BLOCPLAN, layout usulan.

\begin{abstract}
Small and Medium Enterprises (SME) Roti Rizki is a business that focused in bread production, there is bread, sweet bread, and burger bread. The layout facility of the SME Roti Rizki currently does not follow a specific rule in the placement of equipment. Machines that used for the production process, and also not paying attention to the flow of the production process, this inflict for limited space of workers, as well as repetition of activities resulting in waste of time, the production process becomes inefficient which will ultimately reduce production productivity. Method that can be used to solve this problem is the BLOCPLAN method. This method can solve the problem of layout facility in SME Rizki with the level of relations proximity, the needs of the area, calculate the distance of material movement and the final layout. The area of SME Roti Rizki is $100 \mathrm{~m} 2$, the total area needs is $67,599 \mathrm{~m} 2$. There are 20 alternative layouts on the BLOCPLAN method, the recommended layout is elected based on the $R$-Score value that the value is close to 1 , that is the 13th layout with the distance of material moivement savings by 11.3 meters or $3.79 \%$.
\end{abstract}

Keywords: layout facility, BLOCPLAN, recommended layout.

\section{Pendahuluan}

Tata letak fasilitas produksi merupakan salah satu elemen yang berperan penting dalam peningkatan efisiensi perusahaan agar aliran proses produksi dapat berjalan dengan lancar. Menurut Apple (1990), tata letak merupakan tata cara pengaturan fasilitas-fasilitas pabrik guna menunjang kelancaran proses produksi. Pengaturan tersebut akan memanfaatkan luas area (space) untuk penempatan mesin atau fasilitas penunjang produksi lainnya, kelancaran gerakan-gerakan material, penyimpanan material baik yang bersifat temporer maupun permanen, personil pekerja dan sebagainya.

Usaha Kecil Menengah (UKM) Roti Rizki merupakan usaha yang bergerak di bidang produksi roti. UKM ini mendistribusikan roti hampir di seluruh kota Bontang dan sebagian daerah Sangatta. UKM Roti Rizki berlokasi di Tanjung Laut, Kota Bontang, Provinsi Kalimantan Timur. UKM ini memproduksi beberapa jenis roti, di antaranya roti tawar, roti manis, dan roti burger. Jumlah roti yang di produksi pada UKM Roti Rizki 
sekali produksi adalah sekitar 500 pcs, dimana jumlah roti tawar sebanyak 40\%, Roti manis sebanyak $20 \%$, dan roti burger sebanyak $40 \%$. Peralatan yang digunakan pada kegiatan produksi roti yaitu mesin mixer, oven, mesin penggulung adonan, dan mesin pemotong roti. Perancangan tata letak fasilitas yang dilakukan pada lantai produksi UKM Roti Rizki adalah pada proses produksi roti tawar dikarenakan jumlah produksi roti tawar ini merupakan produk yang paling bannyak di produksi selain itu proses kegiatannya juga lebih kompleks daripada roti yang lain. Kegiatan proses produksi roti pada UKM ini diawali dengan penimbangan bahan, pencampuran bahan, penggulungan dan pemotongan adonan roti, pengembangan adonan roti, pemanggangan, pendinginan, pemotongan roti dan pengepakan. Jumlah pekerja pada UKM Roti Rizki saat ini sebanyak 4 orang pekerja.

Luas pabrik yang berfungsi sebagai lantai produksi dan juga sebagai gudang pada UKM Roti Rizki adalah $100 \mathrm{~m} 2$. Tata letak fasilitas pada UKM Roti Rizki saat ini belum mengikuti suatu aturan khusus dalam penempatan peralatan serta mesin-mesin yang digunakan untuk proses produksi tidak memperhatikan aliran proses produksi. Hal ini mengakibatkan ruang gerak para pekerja menjadi terbatas, serta terjadi pengulangan kegiatan yang mengakibatkan pemborosan waktu, proses produksi tidak efisien yang pada akhirnya akan menurunkan produktivitas produksi. Oleh sebab itu, diperlukan perancangan ulang (relayout) tata letak fasilitas produksi pada UKM Roti Rizki agar kegiatan proses produksi dapat berjalan sesuai dengan aliran proses produksinya.

Salah satu metode yang dapat digunakan dalam penyelesaian permasalahan tata letak fasilitas, di antaranya adalah metode Algoritma BLOCPLAN. Menurut Pratiwi, dkk (2012), BLOCPLAN merupakan sistem perancangan tata letak fasilitas yang dikembangkan oleh Donaghey dan Pire pada departemen Teknik Industri, Universitas Houston. Program ini membuat dan mengevaluasi tipe-tipe tata letak dalam merespon data masukan. Metode BLOCPLAN dapat menggunakan peta keterkaitan sebagai input data, biaya tata letak dapat diukur baik berdasarkan ukuran jarak maupun dengan kedekatan. Jumlah baris didalam BLOCPLAN ditentukan oleh program dan biasanya dua atau tiga baris. BLOCPLAN merupakan program yang dikembangkan untuk perancangan tata letak fasilitas menggunakan algoritma hybrid yang menggabungkan antara algoritma konstruktif dan algoritma perbaikan. Fungsi tujuan dari BLOCPLAN adalah meminimasi jarak antara fasilitas atau memaksimalkan hubungan kedekatan antar fasilitas. Hasil perancangan tata letak fasilitas dengan menggunakan metode BLOCPLAN ini didapatkan beberapa alternatif yang dapat dipilih berdasarkan tiga jenis kriteria yang ada, yaitu adjacency score, R-score, dan product movement.

Berdasarkan dari beberapa metode yang ada pada perencanaan tata letak fasilitas maka permasalahan perancangan ulang tata letak pada UKM Roti Rizki dapat diselesaikan dengan metode BLOCPLAN. Penentuan hasil rancangan terbaik dilakukan dengan analisis pemilihan layout berdasarkan nilai R-score tebaik dan juga kesesuaian luas lahan tersedia. Diharapkan permasalahan tata letak yang diselesaikan dengan metode BLOCPLAN pada UKM Roti Rizki ini nantinya dapat meningkatkan produktivitas pada UKM Roti Rizki.

\section{Metode Penelitian}

Menurut Hadiguna (2008), tata letak fasilitas dapat didefinisikan sebagai kumpulan unsur-unsur fisik yang diatur mengikuti aturan atau logika tertentu. Tata letak fasilitas merupakan bagian perancangan fasilitas yang lebih fokus pada pengaturan unsur-unsur fisik. Unsur-unsur fisik dapat berupa mesin, peralatan, meja, bangunan, dan sebagainya. Aturan atau logika pengaturan dapat berupa ketetapan fungsi tujuan misalya total jarak atau total biaya perpindahan bahan.

Menurut Purnomo (2004), BLOCPLAN merupakan sistem perancangan tata letak fasilitas yang dikembangkan oleh Donaghey dan Pire pada departemen Teknik Industri, Universitas Houston. Program ini membuat dan mengevaluasi tipe-tipe tata letak dalam merespon data masukan. BLOCPLAN mempunyai kemiripan dengan CRAFT dalam penyusunan departemen. Perbedaannya adalah metode BLOCPLAN dapat menggunakan peta keterkaitan sebagai input data, sedangkan CRAFT hanya menggunakan peta dari-ke (fromto chart). Biaya tata letak dapat diukur baik berdasarkan ukuran jarak maupun dengan kedekatan. Jumlah baris didalam $B L O C P L A N$ ditentukan oleh program dan biasanya dua atau tiga baris.

Menurut Assauri (2008), BLOCPLAN juga mempunyai kelemahan yaitu tidak akan menangkap initial layout secara akurat. Pengembangan tata letak hanya dapat dicari dengan melakukan perubahan atau pertukaran letak departemen satu dengan lainnya. Selain peta keterkaitan BLOCPLAN kadang-kadang juga menggunakan input data lain yaitu from-to chart, hanya saja kedua input tersebut hanya digunakan salah satu saja saat melakukan evaluasi tata letak. Tata letak tidak dapat dilakukan evaluasi dengan mengkombinasikan kedua data, peta keterkaitan dan data aliran. Langkah-langkah perancangan tata letak dengan metode BLOCPLAN adalah:

Langkah pertama yang harus dilakukan untuk menjalankan program BLOCPLAN adalah dengan memasukkan input data. Informasi yang diperlukan untuk menjalankan BLOCPLAN antara lain jumlah 
departemen, nama-nama departemen, dan luas area masing-masing departemen. Informasi lain yang sangat penting dan sangat diperlukan adalah data keterkaitan masing-masing departemen. Kode atau simbol-simbol keterkaitan yang digunakan di dalam BLOCPLAN menggunakan simbol-simbol yang dikembangkan oleh Muther dalam Systematic Layout Planning (SLP).

Nilai masing-masing simbol keterkaitan departemen sebenarnya ditentukan oleh masing-masing pengguna BLOCPLAN. Sebagai contoh dalam suatu aplikasi pengguna merasa bahwa simbol A mempunyai nilai tiga kali lebih penting dari pada nilai $\mathrm{E}$, namun untuk persoalan lainnya mungkin hanya dua kali lebih penting. Biasanya sistem akan memunculkan nilai simbol-simbol tersebut yang mungkin bisa diterima. Pada gambar 2.1, menunjukkan bahwa simbol A mempunyai harga 10 poin, simbol E berharga 5 poin, simbol I berharga 2 poin, simbol O berharga 1 poin, simbol U berharga nol, dan simbol X mempunyai harga -10 poin. Nilai dari simbolsimbol keterkaitan ini dapat dirubah jika pengguna menginginkan untuk mengubahnya.

Berdasarkan dari peta keterkaitan dan nilai darimerupakan jumlah dari seluruh nilai simbol-simbol keterkaitan, BLOCPLAN akan mengembangkan dan akan menampilkan skor masing-masing departemen untuk persoalan di atas. Skor departemen merupakan jumlah dari seluruh nilai simbol-simbol keterkaitan.

BLOCPLAN akan menampilkan lima buah pilahan rasio panjang dan lebar dari bentuk tata letak yang diinginkan. Rasio yang bisa dipilih masing-masing, untuk pilihan pertama adalah 1,35: 1, pilihan kedua 2: 1, pilihan ketiga 1: 1 , piihan keempat 1:2, pilihan kelima pengguna menentukan sendiri panjang dan lebar yang dikehendaki.

BLOCPLAN akan membuat beberapa alternatif tata letak tergantung keinginan pengguna (maksimum 20 alternatif). Departemen-departemen akan ditempatkan pada area tata letak tertentu secara random. Alternatif tata letak akan ditampilkan dengan skala tertentu dan masing-masing alternatif akan dihitung skornya. Untuk menentukan alternatif tata letak terbaik. Bisa dipilih dengan melihat satu persatu dimulai dari alternatif 1 sampai dengan alternatif terakhir. BLOCPLAN akan menampilkan satu persatu alternatif tata letak tersebut berikut skornya. Skor tertinggi dapat diusulkan sebagai alternatif terbaik.

\section{Hasil dan Pembahasan}

Menurut Wignjosoebroto (2009), ARC sangat berguna untuk perencanaan dan analisis hubungan aktivitas antar masing-masing departemen. Pada dasarnya diagram ini menjelaskan mengenai hubungan pola aliran bahan dan lokasi dari masing-masing departemen penunjang terhadap departemen produksinya. Pada dasarnya ARC ini hampir mirip dengan From To Chart, hanya saja disini analisanya bersifat kualitatif. Kalau pada from to chart analisis dilaksanakan berdasarkan angka-angka berat atau volume dan jarak perpindahan bahan dari satu departemen ke departemen lain, maka ARC akan menggantikan kedua hal tersebut dengan kode huruf yang akan menunjukkan derajat hubungan aktivitas secara kualitatif dan juga kode angka yang akan menjelaskan alasan untuk pemilihan kode huruf tersebut.

Hasil dari perancangan ulang tata letak fasilitas produksi pada UKM Roti di awali dengan membuat ARC yang dapat dilihat pada gambar 1 berikut ini:

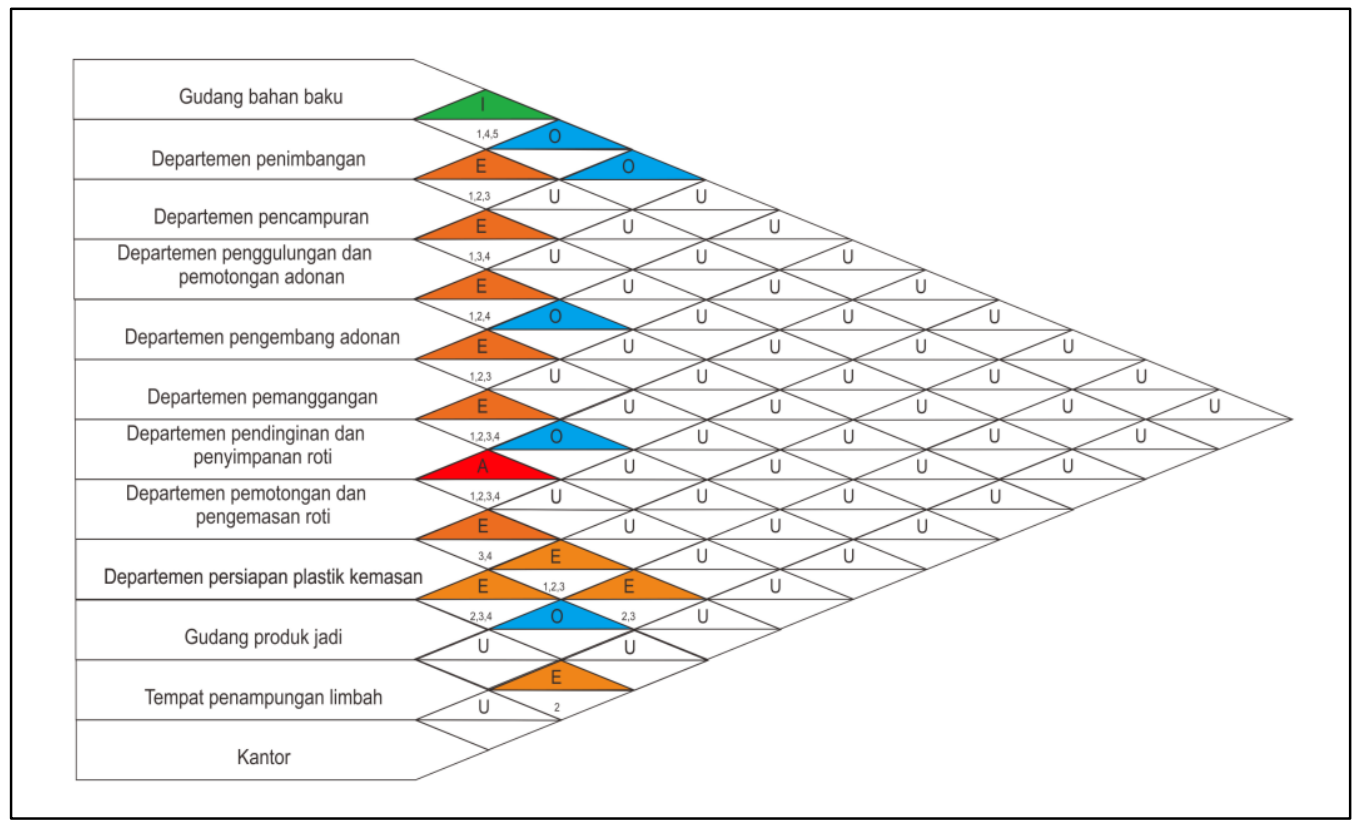

Gambar 1. ARC Produksi UKM Roti Rizki 
Setelah dibuat ARC, langkah selanjutnya adalah input nilai simbol-simbol keterkaitan yang nilainya didapatkan dari ARC. Input nilai simbol-simbol keterkaitan dapat dilihat pada Gambar 2 di berikut ini:

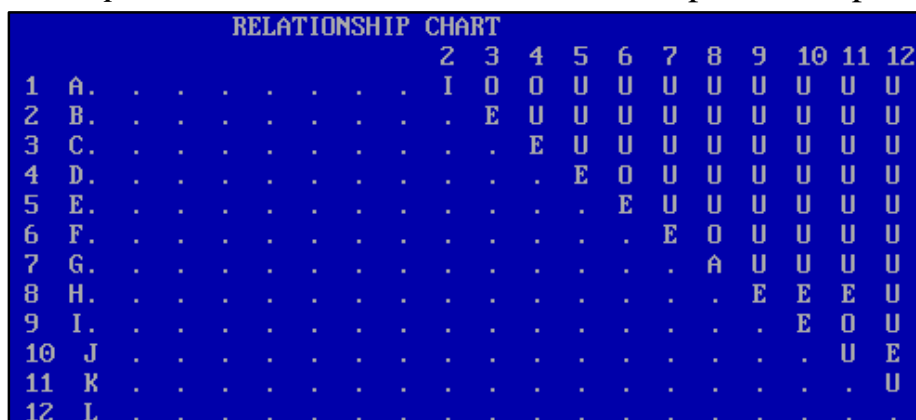

WANT TO CHANGE RELATIONSHIP CHART (Y/N) ? N

Gambar 2. Peta Keterkaitan

. Dalam menentukan nilai skor masing-masing departemen bisa ditentukan oleh masing-masing pengguna BLOCPLAN atau mengikuti nilai yang tekah ditentukan oleh sistem. Nilai dari simbol- simbol keterkaitan dapat dilihan pada Gambar 3 berikut ini:

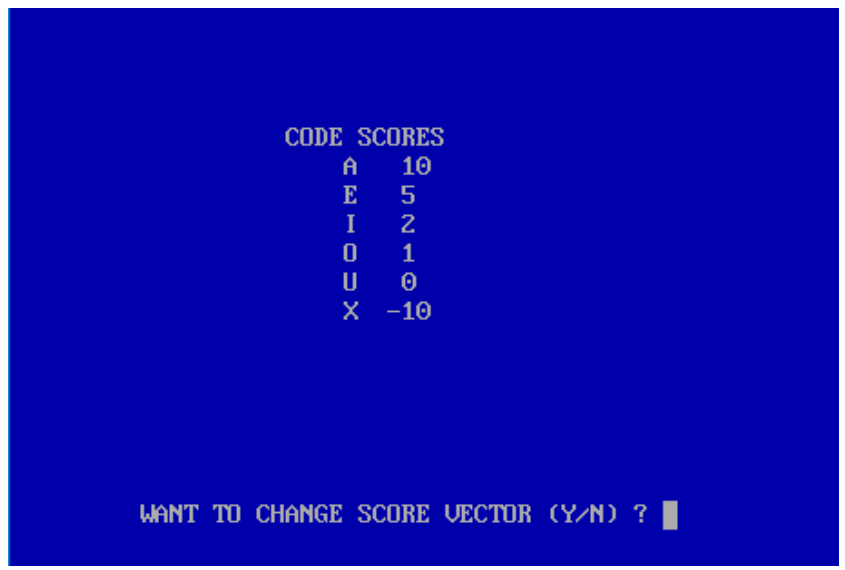

Gambar 3. Nilai Simbol Keterkaitan

BLOCPLAN akan menampilkan lima buah pilihan rasio panjang dan lebar dari bentuk tata letak yang diinginkan, masing-masing dari bentuk tata letak dapat dilihat pada Gambar 4 berikut ini:

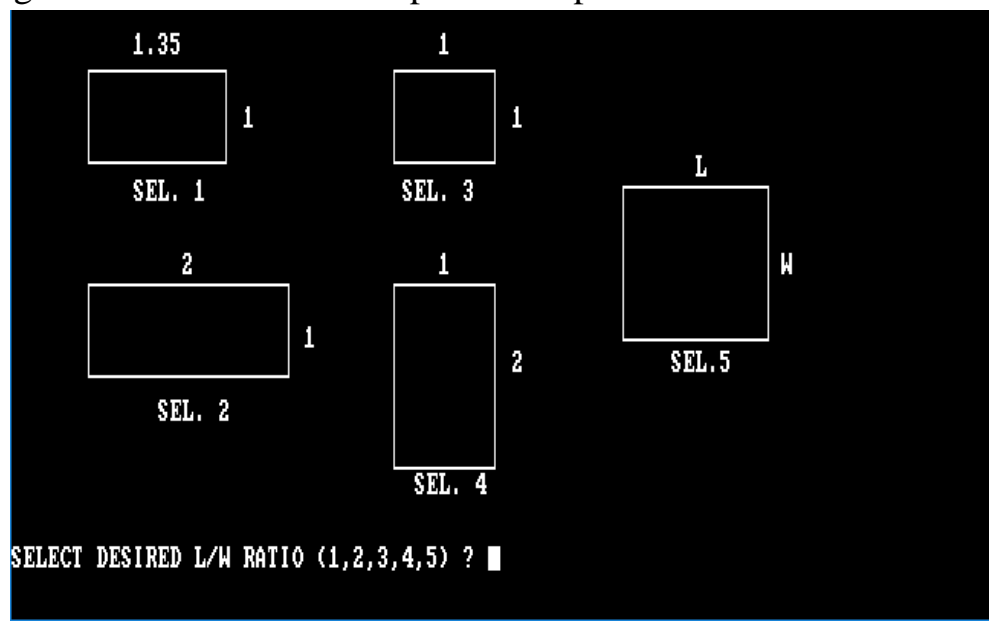

Gambar 4. Bentuk Tata Letak

Berdasarkan dari bentuk tata letak yang telah ditampilkan pada BLOCPLAN, selanjutnya dapat dipilih bentuk tata letak yang diinginkan. Terdapat 5 pilihan rasio dari bentuk tata letak tersebut, di antaranya pilihan pertama 1,35: 1, pilihan kedua 2: 1, pilihan ketiga 1: 1, pilihan keempat 1: 2, dan pilihan kelima merupakan pilihan yang bisa ditentukan sendiri rasio dari bentuk tata letak tersebut. Berdasarkan dari panjang dan lebar 
dari fasilitas produksi UKM Roti Rizki yang memiliki panjang 10 meter dan lebar 10 meter maka rasio dari bentuk tata letak yang dipilih adalah pilihan ketiga dengan rasio 1:1.

BLOCPLAN akan membuat beberapa alternatif tata letak tergantung keinginan pengguna (maksimum 20 alternatif). Masing-masing departemen akan ditempatkan pada area tata letak tertentu secara random, BLOCPLAN akan menampilkan satu persatu alternatif tata letak tersebut berikut skornya. Untuk tata letak terbaik dapat dilihat dari nilai R-SCORE yang tertinggi, apabila nilainya mendekati 1 maka dapat diusulkan sebagai alternatif terbaik. Skor dan masing-masing alternatif tata letak dapat dilihat pada Gambar 5 di bawah ini:

\begin{tabular}{|lcccc}
\hline LAYOUT & ADJ . SCORE & REL-D IST SCORES & PROD MOUEMET \\
1 & $0.88-7$ & $0.76-14$ & $247-18$ & $0-1$ \\
2 & $0.72-19$ & $0.70-19$ & $236-16$ & $0-1$ \\
3 & $0.88-7$ & $0.85-5$ & $188-6$ & $0-1$ \\
4 & $0.82-11$ & $0.84-6$ & $183-5$ & $0-1$ \\
5 & $0.79-14$ & $0.72-17$ & $251-19$ & $0-1$ \\
6 & $0.97-1$ & $0.89-3$ & $169-2$ & $0-1$ \\
7 & $0.85-10$ & $0.89-2$ & $170-4$ & $0-1$ \\
8 & $0.90-5$ & $0.80-11$ & $219-11$ & $0-1$ \\
9 & $0.94-4$ & $0.86-4$ & $189-7$ & $0-1$ \\
10 & $0.73-18$ & $0.77-13$ & $219-12$ & $0-1$ \\
11 & $0.79-14$ & $0.80-10$ & $208-10$ & $0-1$ \\
12 & $0.78-16$ & $0.79-12$ & $228-15$ & $0-1$ \\
13 & $0.96-2$ & $0.91-1$ & $167-1$ & $0-1$ \\
14 & $0.78-16$ & $0.74-15$ & $227-14$ & $0-1$ \\
15 & $0.90-5$ & $0.81-9$ & $223-13$ & $0-1$ \\
16 & $0.88-7$ & $0.82-8$ & $189-8$ & $0-1$ \\
17 & $0.81-13$ & $0.71-18$ & $242-17$ & $0-1$ \\
18 & $0.72-19$ & $0.74-16$ & $207-9$ & $0-1$ \\
19 & $0.96-2$ & $0.84-7$ & $170-3$ & $0-1$ \\
20 & $0.82-11$ & $0.64-20$ & $273-20$ & $0-1$ \\
& & & & TIME PER LAYOUT \\
DO YOU WANT TO DELETE SAUED LAYOUT (Y/N) ? &
\end{tabular}

Gambar 5. Skor Masing-masing Alternatif Tata Letak

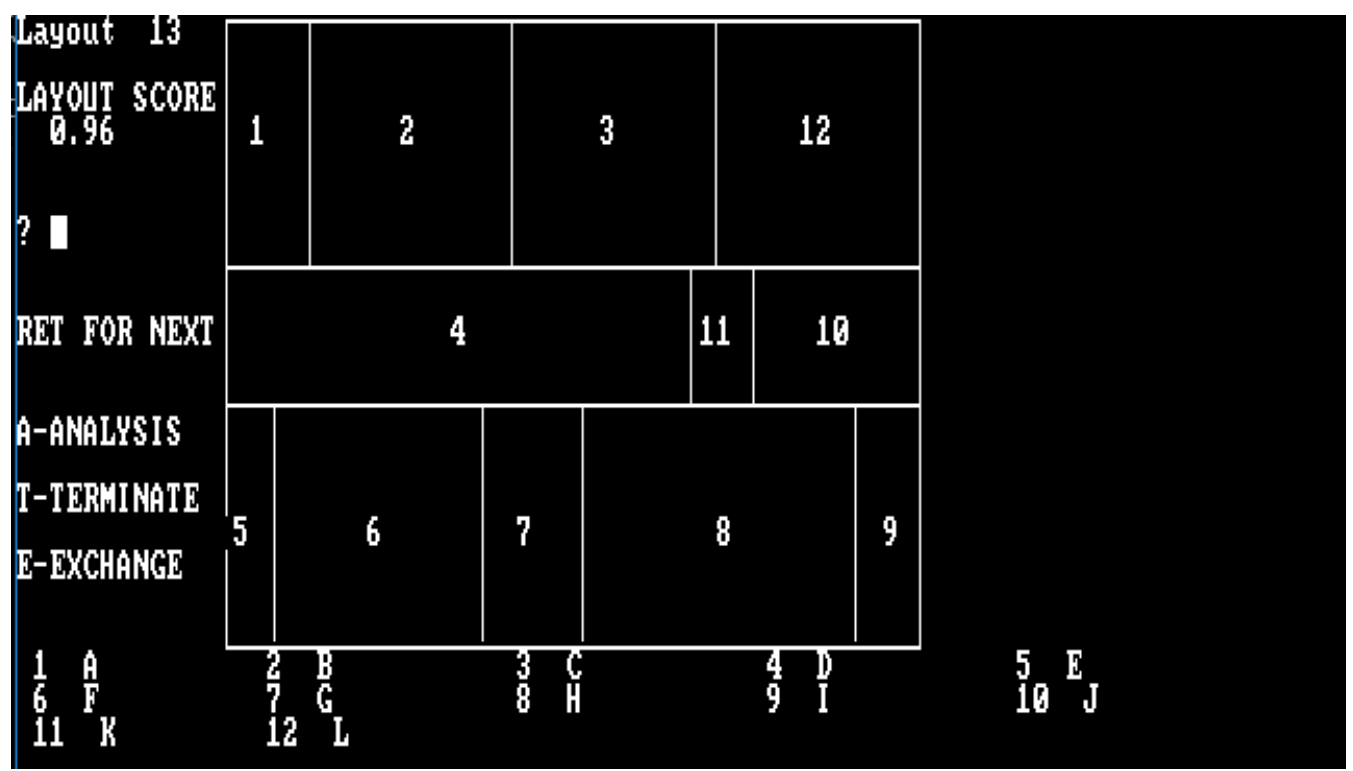

Gambar 6. Output Layout Usulan dari BLOCPLAN

Tabel 1. Fasilitas kerja UKM Roti Riski

\begin{tabular}{cl}
\hline Simbol & \multicolumn{1}{c}{ Fasilitas Kerja } \\
\hline $\mathrm{A}$ & Gudang Bahan Baku \\
$\mathrm{B}$ & Departemen Penimbangan \\
$\mathrm{C}$ & Departemen Pencampuran \\
$\mathrm{D}$ & Departemen penggulungan dan pemotongan adonan \\
$\mathrm{E}$ & Departemen pengembangan adonan \\
$\mathrm{F}$ & Departemen pemanggangan \\
$\mathrm{G}$ & Departemen pendinginan roti \\
$\mathrm{H}$ & Departemen pemotongan dan pengemasan roti \\
$\mathrm{I}$ & Departemen persiapan plastic kemasan \\
$\mathrm{J}$ & Gudang produk jadi \\
$\mathrm{K}$ & Tempat penampungan limbah \\
$\mathrm{L}$ & Kantor \\
\hline
\end{tabular}


Berdasarkan dari hasil pengamatan yang telah dilakukan pada UKM Roti Rizki, kondisi layout awal pada lantai produksi tidak mengikuti suatu aturan khusus. Penempatan mesin serta peralatan produksi tidak mempertimbangkan derajat kedekatan proses produksi sehingga ruang gerak pekerja menjadi terbatas, dan terjadinya pengulangan kegiatan yang mengakibatkan pemborosan waktu. Letak departemen penimbangan dan gudang bahan baku terlalu jauh begitu juga dengan tempat penyimpanan produk jadi yang masih menjadi satu dengan area pendinginan roti sehingga tempat pendinginan roti terkadang menjadi kurang karena masih ada produk jadi yang belum terjual yang masih tersimpan di tempat tersebut.

Berdasarkan dari hasil pengolahan data yang telah dilakukan pada fasilitas produksi UKM Roti Rizki, perancangan ulang tata letak fasilitas produksi dengan menggunakan metode BLOCPLAN terdapat 20 usulan perbaikan tata letak dimana tata letak yang memiliki nilai R-Score tertinggi atau mendekati 1 ada pada layout 13 yang dipilih adalah karena memiliki nilai R-Score tertinggi yaitu senilai 0,91 dan juga nilai Distance score yang lebih kecil yaitu senilai 167. Layout usulan yang baru ini memberikan ruang gerak yang lebih luas di tengah dibandingkan layout awal dan juga terdapat tempat yang bisa dijadikan sebagai tempat penyimpanan produk jadi.

Berdasarkan dari total luas area yang tersedia dan hasil perhitungan kebutuhan luas area produksi pada UKM Roti Rizki dengan menggunakan toleransi 0,5 meter untuk mesin serta allowance $40 \%$ untuk operator didapatkan total luas kebutuhan area produksi seluas 67,599 $\mathrm{m} 2$ maka kebutuhan luas area produksi untuk UKM Roti Rizki sudah tercukupi dari total luas yang tersedia yaitu seluas $100 \mathrm{~m} 2$.

Jarak perpindahan material pada layout awal sebesar 33,41 meter sedangkan pada layout usulan terdapat pengurangan total jarak perpindahan material sebesar 11,35 meter dimana total jarak perpindahan material pada layout usulan sebesar 22,06 meter, maka efisiensi jarak perpindakan material pada UKM Roti Rizki sebesar $3,79 \%$.

Layout usulan pada UKM Roti Rizki memiliki beberapa fasilitas tambahan yaitu berupa gudang produk jadi, tempat penampungan limbah, dan juga kantor. Dengan adanya ruang kantor maka UKM Roti Rizki memiliki tempat khusus untuk pelayanan administrasi, dan juga sebagai tempat receptionist apabila ada konsumen yang ingin membeli roti pada UKM Roti Rizki.

\section{Simpulan dan Saran}

Berdasarkan dari hasil penelitian yang telah dilakukan di UKM roti Riski untuk kebutuhan luas area secara keseluruhan pada UKM Roti Rizki adalah sebesar 67,599 m2 dimana kebutuhan luas area ini sudah tercukupi dari kebutuhan luas area yang tersedia pada UKM Roti Rizki yaitu sebesar $100 \mathrm{~m} 2$. Kebutuhan luas area tersebut sudah mencukupi untuk 12 fasilitas kerja atau departemen. Terdapat 20 alternatif layout usulan yang ada pada metode BLOCPLAN, layout usulan yang dipilih berdasarkan dari nilai R-Score yang nilainya mendekati 1 yaitu layout ke-13 yang dipilih sebagai layout usulan dengan penghematan jarak perpindahan material sebesar 11,35 meter atau sebesar 3,79\%.

Pada penelitian selanjutnya disarankan untuk membahas meminimalkan jarak perpindahan material dengan menggunakan metode lainnya seperti OMH (Ongkos Material Handling) agar mendapatkan jarak perpindahan yang optimal dan juga bisa mengetahui biaya perpindahan dari materialnya, Penelitian ini menggunakan salah satu produk pada UKM Roti Rizki yang dijadikan objek, sedangkan UKM Roti Rizki memproduksi banyak prroduk. Untuk penelitian selanjutnya dapat menggunakan beberapa produk sebagai objek agar penentuan layout bisa lebih detail, Penelitian ini tidak memperhitungkan biaya yang dikeluarkan untuk perancangan ulang tata letak fasilitas pada UKM Roti Rizki, sebaiknya untuk penelitian selanjutnya dapat mempertimbangkan biaya investasi pada layout yang diusulkan.

\section{Daftar Pustaka}

Apple, James M., 1990. Tata Letak Pabrik dan Pemindahan Bahan. edk 3. ITB: Bandung.

Assauri, S. 2008. Manajemen Produksi dan Operasi. edk 4. Penerbit Fakultas Ekonomi Universitas Indonesia: Jakarta.

Hadiguna, dkk, 2008. Tata Letak Pabrik. Penerbit ANDI: Yogyakarta.

Pratiwi, dkk, 2012. Perancangan Tata Letak Fasilitas di Industri Tahu Menggunakan Blocplan. Jurnal Ilmiah Teknik Industri, Vol. 11, No. 2, ISSN 1412-6869.

Purnomo, Hari, 2004. Perencanaan \& Perancangan Fasilitas. Penerbit Graha Ilmu: Yogyakarta.

Wignjosoebroto, S. Tata Letak Pabrik dan Pemindahan Bahan. Edisi ke-3 cetakan ke-4. Guna Widya, Surabaya. 2009. 